\title{
A prenatal case with discrepant findings between non-invasive prenatal testing and fetal genetic testings
}

\author{
Qiong Pan ${ }^{1}$, Baojuan Sun ${ }^{1}$, Xiaoli Huang ${ }^{1}$, Xin Jing ${ }^{1}$, Hailiang Liư ${ }^{3}$, Fuman Jiang ${ }^{4}$, Jie Zhou' ${ }^{1}$, Mengmeng Lin ${ }^{4}$, \\ Hongni Yue ${ }^{1}$, Ping $\mathrm{Hu}^{2^{*}}$ and Ying Ning ${ }^{1 *}$
}

\begin{abstract}
At $17^{+4}$ week, non-invasive prenatal testing (NIPT) results of a 24-years-old mother showed high risk of monosomy $X(45, X)$. Abnormally shaped head and cardiac defects were observed in prenatal ultrasound scan at $19^{+3}$ week. Amniocentesis conducted at $19^{+3}$ week identified karyotype $47, X X,+18$, which suggested that the NIPT failed to detect trisomy 18 (T18) in this case. With a further massively parallel sequencing (MPS) of maternal blood, fetal and placental tissues, we found a confined placental mosaicism (CPM) with non-mosaic T18 fetus and multiclonal placenta with high prevalence of $45, \mathrm{X}$ and low level of T18 cells. FISH and SNP-array evidence from the placental tissue confirmed genetic discrepancy between the fetus and placenta. Because the primary source of the fetal cell-free DNA that NIPT assesses is mostly originated from trophoblast cells, the level of T18 placental mosaicism may cause false negative NIPT result in this rare case of double aneuploidy.
\end{abstract}

Keywords: Non-invasive prenatal testing, Massively parallel sequencing, Mosaicism

\section{Background}

Non-invasive prenatal testing for common fetal aneuploidies, in particular trisomy 21 and 18, by massively parallel sequencing (MPS) of maternal plasma DNA is an extremely efficient screening test with sensitivity and specificity of over 99\% [1].

\section{Case presentation}

Here we report a rare case with mosaic monosomy $\mathrm{X}$ and trisomy 18 in placenta, which induced a false negative NIPT result. Results of the 2nd trimester combined test (AFP $0.65 \mathrm{MoM}$ and hCGb $4.32 \mathrm{MoM}$ ) indicated that the pregnancy of the 24-year-old mother ("gravida 2, para 0", G2P0) was at high risk of Down syndrome (1/45). As the following screening, a NIPT test was then performed at $17^{+4}$ week of gestation by maternal peripheral blood collection,

\footnotetext{
* Correspondence: njfybjyhuping@163.com; rosening@163.com

${ }^{2}$ State key Laboratory of Reproductive Medicine, Department of Prenatal Diagnosis, Nanjing Maternity and Child Health Care Hospital Affiliated to Nanjing Medical University, 123 Tianfei Street, Nanjing 210029, China

'Laboratory of Clinical Genetics, Department of Prenatal Diagnosis, Huaian Maternal and Child Health Care Hospital of Jiangsu Province, Huaian 223002, China

Full list of author information is available at the end of the article
}

cell-free DNA (cfDNA) extraction, library construction and sequencing through Illumina HiSeq2000 platform [2].

However, the NIPT did not reveal risks of fetal trisomy 13,18 or 21 , but demonstrated a great probability of 45 , $\mathrm{X}$. This was a female fetus. The t-score for chromosome 18 was -0.52 , but for chromosome $\mathrm{X}$ was about -4.05 , which suggests that the NIPT result was 45 , X. Ultrasound scan at $19^{+3}$ week showed strawberry-shaped head and ventricular septal defect (VSD) (Figure 1). After consulting, the patient agreed to take a further amniocentesis for confirmation of NIPT results. G-banding of amniocytes cultivation identified the fetal karyotyping result as $47, \mathrm{XX},+18$ (Figure 2) and implied that the NIPT had given a false negative result of T18. After post-test consultation, the couple decided to terminate pregnancy and agreed on additional research. Sequencing results of NIPT (Figure 3) identified the aborted fetal tissue as T18 condition, while the placental tissue as a status of mosaic T18 (mosaic ratio nearly 30\%) and $45, \mathrm{X}$ (mosaic ratio nearly $60 \%$ ), which was in agreement with the amniocentesis result. Moreover, FISH analyses using chromosome 18 and $\mathrm{X}$ specific probes on placental tissues identified a combination of $45, \mathrm{X}$ and $\mathrm{T} 18$ 


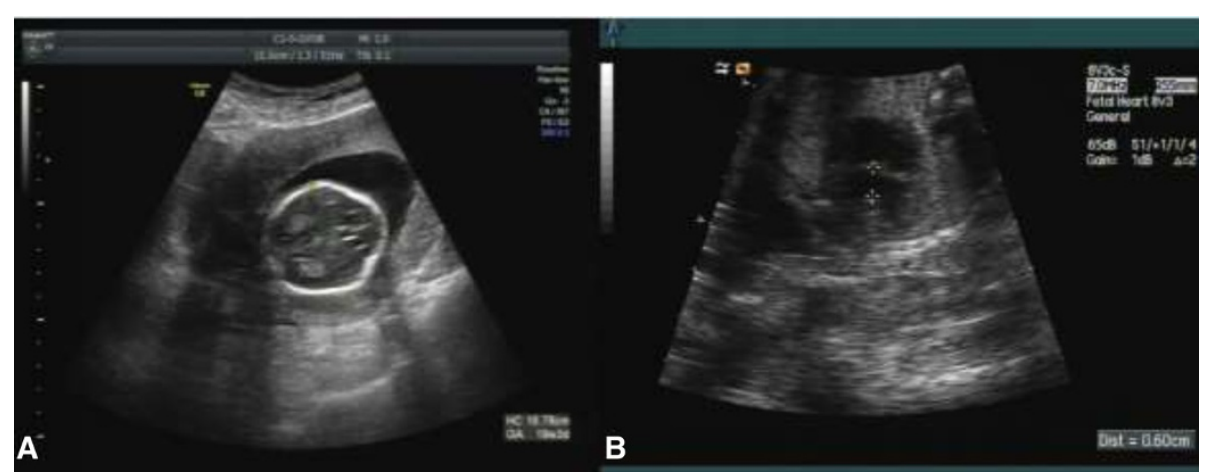

Figure 1 Abnormal sonographic features of fetus at 19th week. A. strawberry-shaped head. B. Four-chamber view of the fetal heart showing a ventricular septal defect $(0.6 \mathrm{~cm}$ diameter).

mosaicism, with high level of $45, \mathrm{X}$ cells $(67 \%, 62 / 92)$ and relatively low abundance of T18 cells $(30 \%, 28 / 92)$ in total (Figure 4). This is also confirmed by SNP-array results of placental samples which offered clear evidence for the various level of 45, X and T18 mosaicism. The SNP-array results (Figure 5) with the signal intensity $(\log \mathrm{R})$ and genotyping (B allele frequency, BAF) value plots indicated the mosaic rearrangements. The increased $\log \mathrm{R}$ and altered $\mathrm{BAF}$ value (Figure $5 \mathrm{~B}$ ) suggested a mosaic trisomy of chromosome 18 in $50 \%$ of the cells. The level of mosaicism was determined based on both $\log R$ and BAF value [3]. Notably, the result indicated partial duplication for the distal section of 18q represented in $17 \%$ of the cells, which was evidenced by the observation of two additional chromatin segments attached to a chromosome 18 in the FISH results (Figure 4). On the other hand, large mosaic deletion ranging in size from 31.05 to $93.16 \mathrm{Mb}$ of chromosome $\mathrm{X}$ was illustrated in Figure $5 \mathrm{C}$. The decreased $\log \mathrm{R}$ and abnormal heterozygous $\mathrm{BAF}$ value indicated a mosaic monosomy at the level of $67 \%$, which showed good agreement with the FISH results.

To the contrary, G-banding, FISH and SNP-array analyses on the post-mortem fetal tissue all demonstrated positive results of complete T18, showing that the fetal tissue is genetically different from the placental tissue.

\section{Analysis and conclusion}

It is acknowledged that fetal cfDNA in maternal peripheral blood is originated from trophoblast and mainly

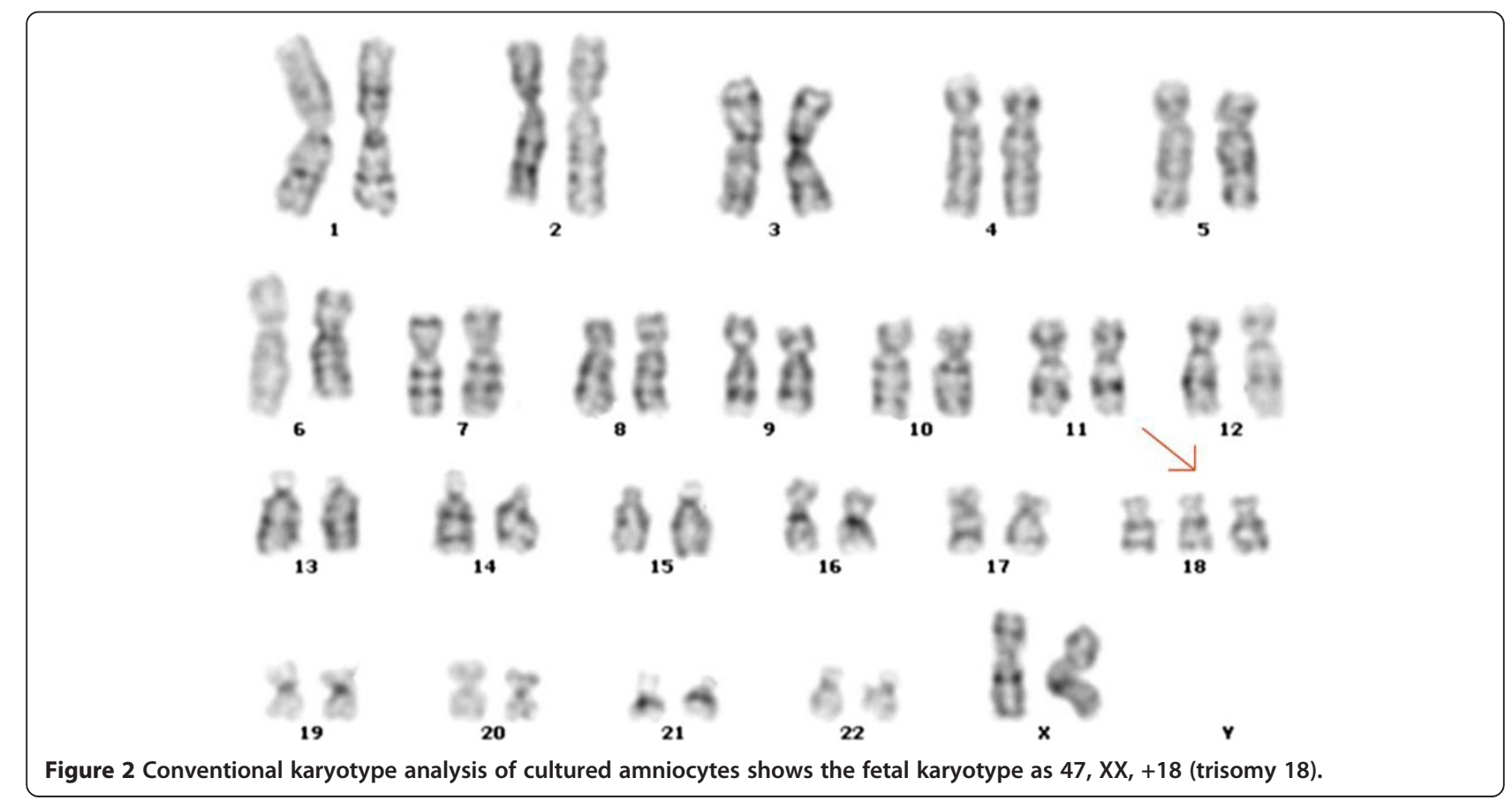




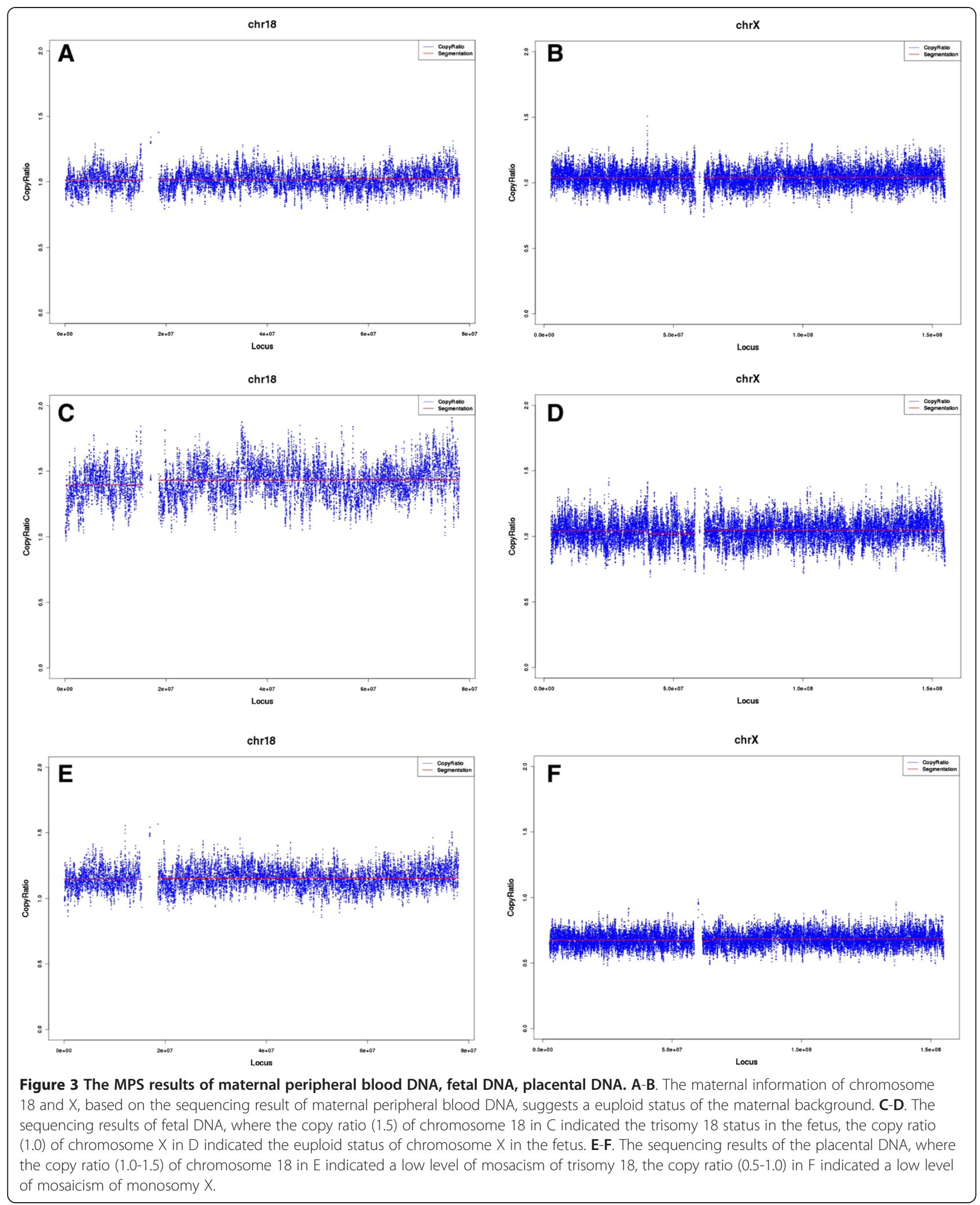




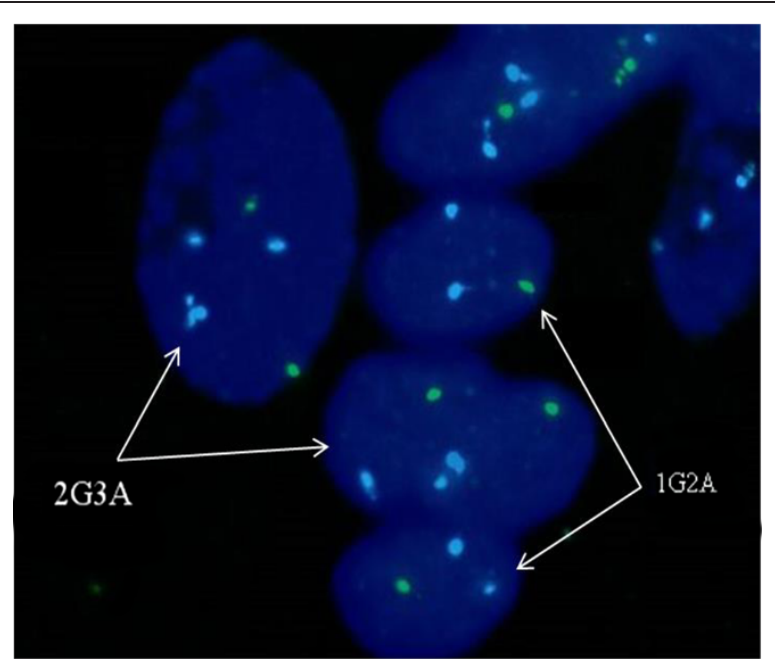

Figure 4 FISH analysis results of placental tissue showed the combination status of $45, X$ and trisomy 18 mosaicism, with DNA of chromosome 18 marked as aqua (A) and chromosome $X$ as green (G). The cells with karyotype $47, X X,+18$ were indicated as $2 \mathrm{G} 3 \mathrm{~A}$, while the $45, X$ cells were indicated as 1G2A. Two additional chromatin segments attached to a chromosome 18 were observed in a cell (2G3A) on the left, suggesting partial duplications in addition to trisomy 18.

consists of placental DNA [4,5]. However, the genetic discordance between placental and fetal tissue may affect the NIPT test and lead to inaccurate results. False positive NIPT results, small but not negligible, have been reported and noted for concern in these years [6-8]. In addition, mosaic condition of placenta may reduce the measurement accuracy and cause false negative result. The present case offered strong evidence for the idea and was supported by a previous case of double trisomy in placenta [9]. In this case, the fraction of fetal cfDNA for T18

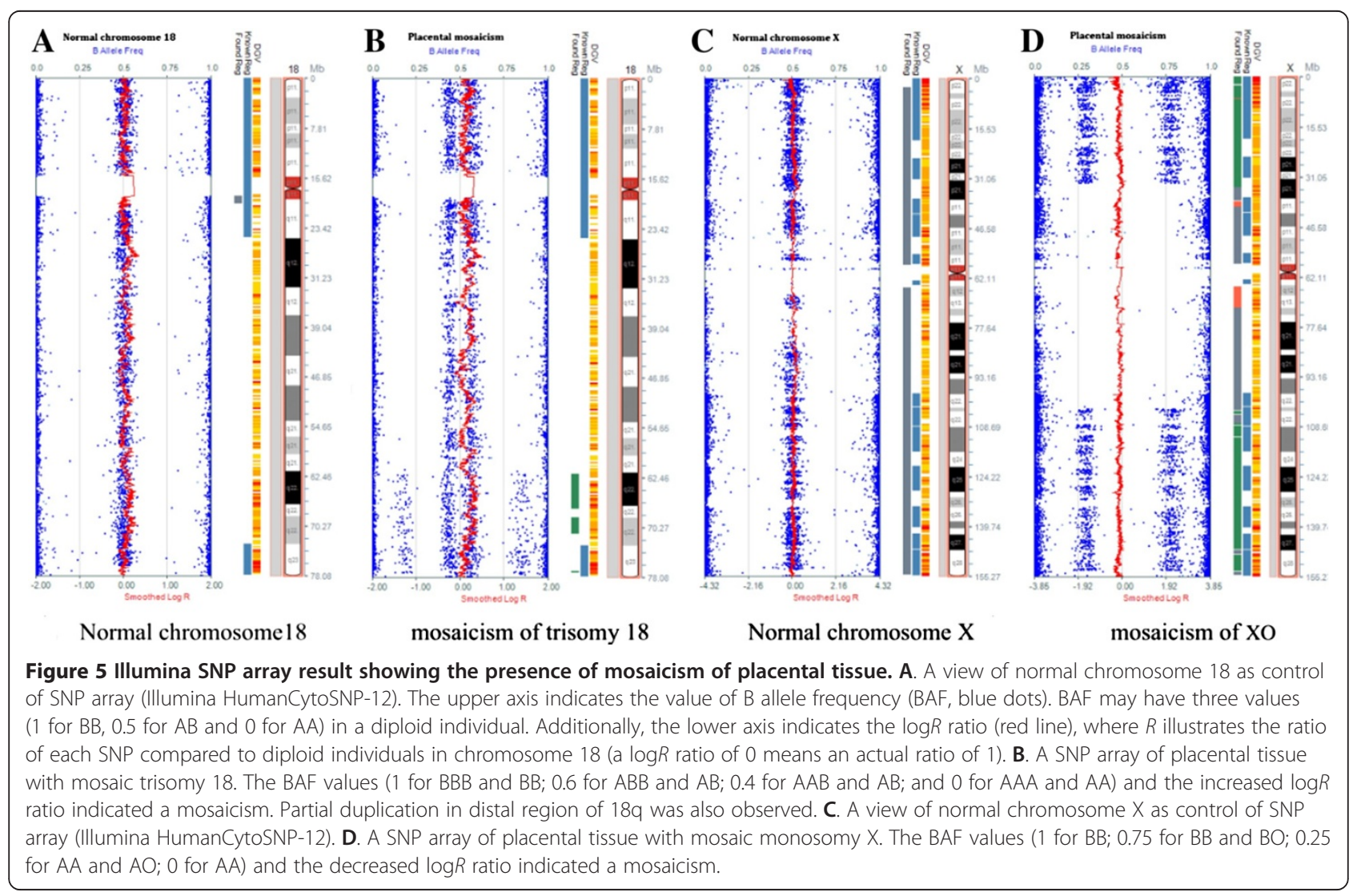


caused by mosaic placenta is considerably lower than the detection threshold of NIPT test and consequently caused false negative results. Therefore, the level of mosaicism is an important factor for the NIPT test.

Collectively, considering the effect from placenta, the NIPT results should be interpreted combining other clinical tests under comprehensive background information.

\section{Consent}

Informed consent was obtained from the patient for publication of this case report and any accompanying images. The sample collection procedures are approved by Huai'an Maternal and Child Health Care Hospital Medical Ethics Committee.

\section{Abbreviations}

NIPT: Non-invasive prenatal testing; MPS: Massively parallel sequencing; CPM: Confined placental mosaicism; FISH: Fluorescence in situ hybridization; cfDNA: Cell-free DNA.

\section{Competing interests}

The authors declare that they have no competing interests.

\section{Authors' contributions}

PQ carried out the molecular genetic studies and drafted the manuscript. SBJ, $H X L$ and YHN reviewed all the clinical data and genetic counseling. JX, JFM, ZJ, LMM did the molecular cytogenetic analysis. HL helped to draft the manuscript, HP supervised the design of the SNP-array. NY supervised the laboratory work and helped to draft the manuscript. All authors read and approved the final manuscript.

\section{Acknowledgement}

We thank the patient for participating in this study.This research was supported by the Major project in maternal and child health care,Jiangsu Province Department of Health of China (Grant no. F201214), and the Development Program for Technological Innovation and Platform Construction, HuaiAn City of China (Grant no. HAP201016).

\section{Author details}

${ }^{1}$ Laboratory of Clinical Genetics, Department of Prenatal Diagnosis, Huaian Maternal and Child Health Care Hospital of Jiangsu Province, Huaian 223002, China. ${ }^{2}$ State key Laboratory of Reproductive Medicine, Department of Prenatal Diagnosis, Nanjing Maternity and Child Health Care Hospital Affiliated to Nanjing Medical University, 123 Tianfei Street, Nanjing 210029, China. ${ }^{3}$ iGenomics, Guangzhou, China. ${ }^{4}$ BGI-Shenzhen, Shenzhen, China.

Received: 14 March 2014 Accepted: 4 June 2014

Published: 16 July 2014

\section{References}

1. Ehrich M, Deciu C, Zwiefelhofer T, Tynan JA, Cagasan L, Tim R, Lu V, McCullough R, McCarthy E, Nygren AO, Dean J, Tang L, Hutchison D, Lu T, Wang $\mathrm{H}$, Angkachatchai $\mathrm{V}$, Oeth $\mathrm{P}$, Cantor CR, Bombard A, van den Boom D: Noninvasive detection of fetal trisomy 21 by sequencing of DNA in maternal blood: a study in a clinical setting. Am J ObstetGynecol 2011, 204(3):205-e1.

2. Jiang F, Ren J, Chen F, Zhou Y, Xie J, Dan S, Su Y, Yin B, Su W, Zhang H, Wang W, Chai X, Lin L, Guo H, Li Q, Li P, Yuan Y, Pan X, Li Y, Liu L, Chen H, Xuan Z, Chen S, Zhang C, Tian Z, Zhang Z, Jiang H, Zhao L, Zheng W, Li S, et al: Noninvasive Fetal Trisomy (NIFTY) test: an advanced noninvasive prenatal diagnosis methodology for fetal autosomal and sex chromosomal aneuploidies. BMC Med Genomics 2012, 5:57.

3. Rodríguez-Santiago B, Malats N, Rothman N, Armengol L, Garcia-Closas M, Kogevinas M, Villa O, Hutchinson A, Earl J, Marenne G, Jacobs K, Rico D, Tardón A, Carrato A, Thomas G, Valencia A, Silverman D, Real FX, Chanock SJ, Pérez-Jurado LA: Mosaic uniparental disomies and aneuploidies as large structural variants of the human genome. Am J Hum Genet 2010, 87(1):129-138

4. Alberry M, Maddocks D, Jones M, Abdel Hadi M, Abdel-Fattah S, Avent N, Soothill PW: Free fetal DNA in maternal plasma in anembryonic pregnancies: confirmation that the origin is the trophoblast. Prenat Diagn 2007, 27(5):415-418.

5. Bianchi DW: Circulating fetal DNA: its origin and diagnostic potential-a review. Placenta 2004, 25:S93-S101.

6. Reiss RE, Cherry AM: Still a screening test: more attention needed to noninvasive prenatal test false-positive rates. Am J Obstet Gynecol 2013, 209(2):160-161.

7. Choi H, Lau TK, Jiang FM, Chan MK, Zhang HY, Lo PS, Chen F, Zhang L, Wang W: Fetal aneuploidy screening by maternal plasma DNA sequencing: 'false positive' due to confined placental mosaicism. Prenat Diagn 2013, 33(2):198-200.

8. Wang Y, Zhu J, Chen Y, Lu S, Chen B, Zhao X, Wu Y, Han X, Ma D, Liu Z, Cram D, Cheng W: Two cases of placental T21 mosaicism: challenging the detection limits of non-invasive prenatal testing. Prenat Diagn 2013, 33(12):1207-1210.

9. Gao Y, Stejskal D, Jiang F, Wang W: False-negative trisomy 18 non-invasive prenatal test result due to $48, \mathrm{XXX},+18$ placental mosaicism. Ultrasound Obstet Gynecol 2014, 43(4):477-478.

doi:10.1186/1755-8166-7-48

Cite this article as: Pan et al:: A prenatal case with discrepant findings between non-invasive prenatal testing and fetal genetic testings. Molecular Cytogenetics 2014 7:48.

\section{Submit your next manuscript to BioMed Central and take full advantage of:}

- Convenient online submission

- Thorough peer review

- No space constraints or color figure charges

- Immediate publication on acceptance

- Inclusion in PubMed, CAS, Scopus and Google Scholar

- Research which is freely available for redistribution 